\title{
Uric Acid - A Uremic Toxin?
}

\author{
Takahiko Nakagawa Marilda Mazzali Duk-Hee Kang \\ L. Gabriela Sánchez-Lozada Jaime Herrera-Acosta Richard J. Johnson \\ Division of Nephrology, Hypertension and Transplantation, University of Florida, Gainesville, Fla., USA
}

\section{Key Words \\ Uric acid · Glomerular hypertension · Endothelial dysfunction - Vascular smooth muscle cell}

\begin{abstract}
Uric acid might often be regarded as a simple marker of renal disease. Although it is well known that hyperuricemia causes gout which is associated with renal insufficiency and cardiovascular disease, one might think that it could attribute to the intrarenal urate crystal, but not to uric acid per se. In order to clarify the role of uric acid in the kidney, we hypothesized that uric acid causes renal disease. To generate mild hyperuricemia without intrarenal crystal in rats, we used low doses of an uricase inhibitor (2\% oxonic acid). Hyperuricemia induced systemic hypertension, glomerular hypertrophy/hypertension, afferent arteriolar sclerosis, and macrophage infiltration in normal rat kidney. In progressive renal disease, such as cyclosporine nephropathy and remnant kidney in rat, uric acid accelerated the progression of renal disease. Thus, we concluded that uric acid is not a simple marker, but a cause of renal disease.
\end{abstract}

Copyright (C) 2006 S. Karger AG, Basel

Uric acid has long been associated with hypertension and renal disease. In his classic paper published in 1879, Mahomed first noted that subjects with hypertension frequently came from gouty families, leading him to suggest uric acid as a causal factor in the blood pressure response [1]. However, most authorities have regarded uric acid as only a marker of cardiovascular and renal disease, particularly since a number of epidemiologic studies have shown that uric acid is not an independent risk factor for cardiovascular disease [2]. Although the association between uric acid and renal dysfunction was even noted by Garrod et al. [3] when discovering that hyperuricemia was the cause of gout, many have regarded the relationship as largely due to renal dysfunction resulting in decreased excretion of uric acid with a consequent elevation in plasma concentrations [4, 5]. Similarly, while subjects with gout frequently have evidence of renal insufficiency and chronic renal disease on biopsy, it has been argued that the renal disease is the consequence of hypertension-induced renal damage and the effects of aging [6].

Nevertheless, there is emerging evidence that chronic elevations of uric acid may cause renal disease. For example, elevated uric acid predicts the development of renal disease both in the general population, as well as in patients with immunoglobulin A nephropathy [7-9].

In one study, the risk of developing renal insufficiency was greater for a subject with uric acid $>8 \mathrm{mg} / \mathrm{dl}$ than with proteinuria [10]. Although there is increasing clinical evidence implicating a role for uric acid in renal disease, it remains unclear if uric acid is pathogenic or whether the renal disease may be due to associated hypertension- or aging-related renal injury.

\section{KARGER}

Fax +4161306 1234

E-Mail karger@karger.ch

www.karger.com
(C) 2006 S. Karger AG, Basel

0253-5068/06/0241-0067\$23.50/0

Accessible online at:

www.karger.com/bpu
Takahiko Nakagawa, MD, $\mathrm{PhD}$

Division of Nephrology, Hypertension and Transplantation, University of Florida PO Box 100224

Gainesville, FL 32610-0224 (USA)

Tel. +1 352392 2448, Fax +1 352392 5465, E-Mail nakagt@medicine.ufl.edu 
Fig. 1. Glomerular sclerosis develops in hyperuricemic rats at 6 months. Normal glomerulus from rat (a), glomerular sclerosis evident in the hyperuricemic rat (b). Prolonged hyperuricemia increases glomerular sclerosis compared with normouricemia (c). $* \mathrm{p}<0.05$ versus control.
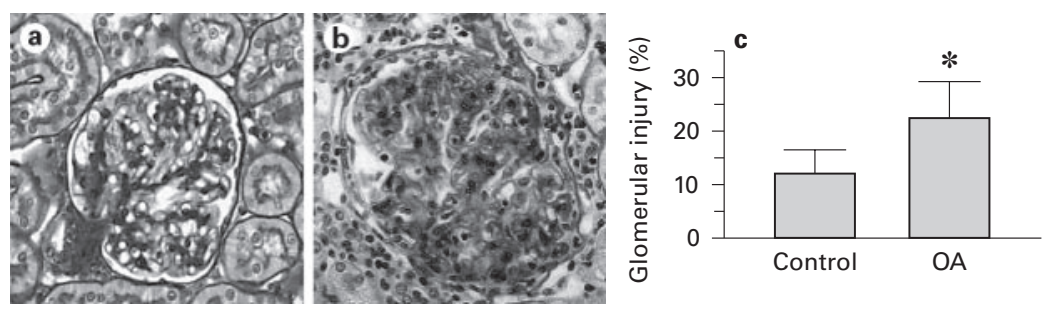

Thus, to examine the causal role of uric acid in renal disease, we have performed studies in rats with experimentally induced hyperuricemia.

\section{Animal Models of Hyperuricemia}

One way to evaluate uric acid as a risk factor is to determine the effects of raising uric acid in experimental animal models. However, when hyperuricemia was produced in mice by deletion of the uricase gene, which is the enzyme required to degrade uric acid to allantoin, the animals developed a marked rise in serum uric acid and acute renal failure due to urate crystal deposition and tubular obstruction [11]. Thus, in these studies, it was difficult to dissect the role of mild elevations in uric acid and their effects on cardiovascular disease from the severe effects related to urate crystal formation.

We have been able to generate mild hyperuricemia without intrarenal crystal deposition in rats by administering low doses of an uricase inhibitor ( $2 \%$ oxonic acid; $\mathrm{OA})$ [12]. This maneuver resulted in a 2-fold increment of serum uric acid. Interestingly, the hyperuricemic animals developed hypertension and microvascular disease (an arteriolosclerosis-like lesion). Using this model, we investigated the role of uric acid in both normal rats and rats with preexisting renal disease. The two models of renal disease employed were the remnant kidney (RK) model in which one complete and two thirds of the other kidney are removed, resulting in a remnant kidney which hypertrophies and scars over 4-8 weeks [13]. The other model selected was the model of cyclosporine (CsA) nephropathy induced in rats using daily subcutaneous injections of CsA in the setting of a low-salt diet [14].

\section{Role of Uric Acid in Normal Kidney}

As discussed above, hyperuricemia was induced by administering a uricase inhibitor $(2 \% \mathrm{OA})$ to normal
Sprague-Dawley rats. Serum uric acid levels ranged from 1.7 to $3.0 \mathrm{mg} / \mathrm{dl}$ at 2 weeks, compared with normal controls that had levels of $0.5-1.4 \mathrm{mg} / \mathrm{dl}$. Systolic blood pressure significantly increased in hyperuricemic rats and was significant at 4 weeks, compared with controls (147 \pm 16 vs. $127 \pm 15 \mathrm{~mm} \mathrm{Hg} ; \mathrm{p}<0.05)$. This increase in blood pressure was completely prevented by lowering serum uric acid with either allopurinol (xanthine oxidase inhibitor) or benziodarone (a uricosuric agent) [12].

The effect of chronic hyperuricemia on kidney structure and function was evaluated at 7 weeks in the OA model $[5,12,15]$. OA-treated rats continued to display higher serum uric acid levels compared with controls (1.8 \pm 0.02 vs. $1.4 \pm 0.02 \mathrm{mg} / \mathrm{dl} ; \mathrm{p}<0.05)$. Renal function was mildly decreased in the hyperuricemic rats, measured by blood urea nitrogen $(23.2 \pm 2.3$ vs. $14.4 \pm 1.2 \mathrm{mg} / \mathrm{dl}$; $\mathrm{p}<0.05)$ [12]. Hyperuricemic rats also demonstrated glomerular hypertrophy $\left(8,200\right.$ vs. $6,016 \mu^{2} /$ glomerular tuft; $\mathrm{p}<0.01$ ) [15], glomerular hypertension (56 \pm 2 vs. $47 \pm 1 \mathrm{~mm} \mathrm{Hg} ; \mathrm{p}<0.01$ ) [5], mild tubulointerstitial injury along with monocyte infiltration (ED1-positive cell infiltration, $0.9 \pm 0.06$ vs. $1.62 \pm 0.2$ cells $/ \mathrm{mm}^{2} ; \mathrm{p}<0.05$ ) [12] and the development of mild vascular disease involving the preglomerular arterioles. Afferent arterioles were nearly $35 \%$ thicker than controls. These findings were prevented by treatment with allopurinol or benziodarone [16]. Moreover, long-term treatment with 2\% OA (for 6 months) induced severe glomerular sclerosis (fig. 1) and higher albuminuria (fig. 2) [15]. Interestingly, hyperuricemia increased juxtaglomerular renin expression, reduced plasma nitric oxide production, and decreased expression of neuronal nitric oxide synthase in the macula densa [12]. The increase in blood pressure and renal vascular changes could be prevented by lowering uric acid with allopurinol or by treatment with an angiotensin-converting enzyme inhibitor [12]. These alterations in vasoactive mediators are likely the mechanisms by which uric acid induced systemic hypertension as well as renal injury. 


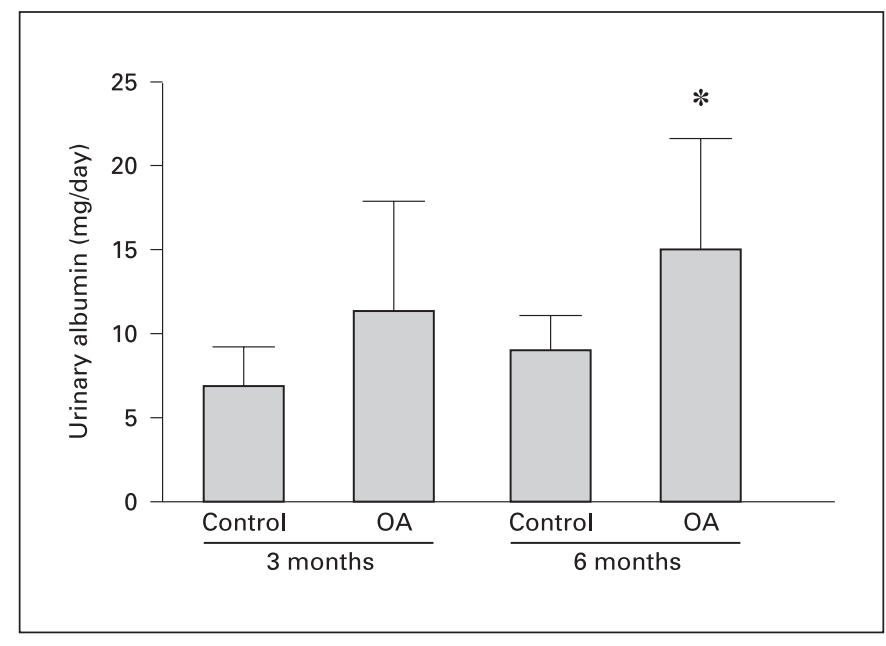

Fig. 2. Prolonged hyperuricemia is associated with the development of microalbuminuria. $* \mathrm{p}<0.05$ versus control (6 months).

\section{Role of Uric Acid in the Progression of Chronic Renal} Disease

To examine if uric acid accelerates the progression of existing chronic renal disease, we induced hyperuricemia in two different kinds of progressive renal diseases in the rat.

\section{RK Model}

Hyperuricemia was induced in rats with RK [13]. In this model, comparing RK + OA with RK, a modest increase in uric acid was observed at 2 weeks $(4.0 \pm 0.6$ vs. $2.7 \pm 0.6 \mathrm{mg} / \mathrm{dl} ; \mathrm{p}<0.01)$ and remained elevated until 6 weeks $(3.2 \pm 0.6$ vs. $1.4 \pm 0.5 \mathrm{mg} / \mathrm{dl} ; \mathrm{p}<0.01)$. In the kidney, more severe glomerulosclerosis ( 24 vs. $17 \%$ of total glomeruli; $\mathrm{p}<0.05)$ and more intensive tubulointerstitial fibrosis ( 1.8 vs. 1.5 score; $p<0.05$ ) were observed in hyperuricemic rats. Vascular injury was also prominent in preglomerular vessels along with cell proliferation of vascular smooth muscle cells (VSMC) and endothelial cells. Furthermore, accentuation of renal arteriolopathy in 5/6 nephrectomy rats with hyperuricemia was associated with severe cortical vasoconstriction and persistent glomerular hypertension [17]. The renal injury in hyperuricemic rats was prevented by lowering uric acid with either allopurinol or benziodarone. To explore the mechanism by which uric acid causes vascular injury, VSMC were stimulated by uric acid. Interestingly, in vitro studies confirmed that uric acid directly stimulates VSMC proliferation as well as monocyte chemoattractant protein 1 expression in VSMC [18].

\section{CsA Nephropathy}

CsA-treated rats developed mild hyperuricemia with arteriolar hyalinosis, tubular injury, and interstitial fibrosis. Treatment with OA enhanced the CsA-induced hyperuricemia without causing intrarenal crystal formation [14]. The chronic hyperuricemia was associated with more severe arteriolar hyalinosis and tubulointerstitial damage. Both the activation of intrarenal renin and the inhibition of endogenous nitric oxide synthase were more evident in 2\% OA-treated CsA nephropathy compared with CsA nephropathy or controls [14].

\section{Overview}

Several lines of studies have shown that hyperuricemia is associated with kidney disease. In the general population, an elevation of uric acid is correlated with decreased renal function $[10,19]$, which is thought to be due to decreased renal blood flow [4]. Uric acid is also associated with renal dysfunction in hypertensive patients [20], as well as with microalbuminuria in type 2 diabetes [21]. In addition, it has been recently shown that a high uric acid level is correlated with renal prognosis and histological changes, such as tubulointerstitial injury or intrarenal arterial lesion in immunoglobulin A nephropathy [7-9]. Interestingly, uric acid may be a more sensitive indicator than serum creatinine for hypertensive target organ damage [22] and may also be a better marker of progressive renal disease than proteinuria [10]. On the other hand, there are some studies showing that uric acid is not an independent risk factor for loss of kidney function [23].

However, the recent experimental evidence suggests that chronic hyperuricemia may be a true renal risk factor. As discussed above, chronically hyperuricemic rats develop hypertension, proteinuria, preglomerular vascular disease, glomerular hypertension, and eventually glomerulosclerosis and tubulointerstitial fibrosis. Hyperuricemia can also exacerbate renal disease in animals with remnant kidneys or with chronic CsA toxicity. This injury may be driven by uric acid-induced endothelial dysfunction, activation of the renin-angiotensin system, and the development of glomerular hypertension and renal vasoconstriction.

Given the current evidence, we recommend that controlled clinical trials should be performed to determine if lowering uric acid may be an additional treatment strategy for slowing the progression of renal disease. Since both asymptomatic hyperuricemia and modest renal injury are common in our society, performing such a study is all the more compelling. 


\section{References}

1 Johnson RJ, Feig DI, Herrera-Acosta J, Kang $\mathrm{DH}$ : Resurrection of uric acid as a causal risk factor in essential hypertension. Hypertension 2005;45:18-20.

-2 Culleton BF, Larson MG, Kannel WB, Levy D: Serum uric acid and risk for cardiovascular disease and death: the Framingham Heart Study. Ann Intern Med 1999;131:7-13.

3 Garrod PR, McSwiney RR, Bold AM: Investigation of renal excretion of phosphate and urate. Clin Sci 1966;31:9-17.

$\checkmark 4$ Messerli FH, Frohlich ED, Dreslinski GR, Suarez DH, Aristimuno GG: Serum uric acid in essential hypertension: an indicator of renal vascular involvement. Ann Intern Med 1980; 93:817-821.

5 Sanchez-Lozada LG, Tapia E, Avila-Casado C, Soto V, Franco M, Santamaria J, Nakagawa T, Rodriguez-Iturbe B, Johnson RJ, HerreraAcosta J: Mild hyperuricemia induces glomerular hypertension in normal rats. Am J Physiol Renal Physiol 2002;283:F1105-F1110.

-6 Touitou Y, Touitou C, Bogdan A, Reinberg A, Motohashi Y, Auzeby A, Beck H: Circadian and seasonal variations of electrolytes in aging humans. Clin Chim Acta 1989;180:245-254.

$\checkmark 7$ Wu J, Chen X, Xie Y, Yamanaka N, Shi S, Wu D, Liu S, Cai G: Characteristics and risk factors of intrarenal arterial lesions in patients with IgA nephropathy. Nephrol Dial Transplant 2005;20:719-727.

$>8$ Ohno I, Hosoya T, Gomi H, Ichida K, Okabe $\mathrm{H}$, Hikita M: Serum uric acid and renal prognosis in patients with IgA nephropathy. Nephron 2001;87:333-339.

$>9$ Myllymaki J, Honkanen T, Syrjanen J, Helin H, Rantala I, Pasternack A, Mustonen J: Uric acid correlates with the severity of histopathological parameters in IgA nephropathy. Nephrol Dial Transplant 2005;20:89-95.
10 Iseki K, Oshiro S, Tozawa M, Iseki C, Ikemiya Y, Takishita S: Significance of hyperuricemia on the early detection of renal failure in a cohort of screened subjects. Hypertens Res 2001; 24:691-697.

Wu X, Wakamiya M, Vaishnav S, Geske R, Montgomery C Jr, Jones P, Bradley A, Caskey CT: Hyperuricemia and urate nephropathy in urate oxidase-deficient mice. Proc Natl Acad Sci USA 1994;91:742-746.

12 Mazzali M, Hughes J, Kim YG, Jefferson JA, Kang DH, Gordon KL, Lan HY, Kivlighn S, Johnson RJ: Elevated uric acid increases blood pressure in the rat by a novel crystal-independent mechanism. Hypertension 2001;38: 1101-1106.

13 Kang DH, Nakagawa T, Feng L, Watanabe S, Han L, Mazzali M, Truong L, Harris R, Johnson RJ: A role for uric acid in the progression of renal disease. J Am Soc Nephrol 2002;13: 2888-2897.

14 Mazzali M, Kim YG, Suga S, Gordon KL, Kang DH, Jefferson JA, Hughes J, Kivlighn SD, Lan HY, Johnson RJ: Hyperuricemia exacerbates chronic cyclosporine nephropathy. Transplantation 2001;71:900-905.

15 Nakagawa T, Mazzali M, Kang DH, Kanellis J, Watanabe S, Sanchez-Lozada LG, Rodriguez-Iturbe B, Herrera-Acosta J, Johnson RJ: Hyperuricemia causes glomerular hypertrophy in the rat. Am J Nephrol 2003;23:2-7.

16 Mazzali M, Kanellis J, Han L, Feng L, Xia YY, Chen Q, Kang DH, Gordon KL, Watanabe S, Nakagawa T, Lan HY, Johnson RJ: Hyperuricemia induces a primary renal arteriolopathy in rats by a blood pressure-independent mechanism. Am J Physiol Renal Physiol 2002;282: F991-F997.
17 Sanchez-Lozada LG, Tapia E, Santamaria J, Avila-Casado C, Soto V, Nepomuceno T, Rodriguez-Iturbe B, Johnson RJ, Herrera-Acosta $\mathrm{J}$ : Mild hyperuricemia induces vasoconstriction and maintains glomerular hypertension in normal and remnant kidney rats. Kidney Int 2005;67:237-247.

18 Kanellis J, Watanabe S, Li JH, Kang DH, Li P, Nakagawa T, Wamsley A, Sheikh-Hamad D, Lan HY, Feng L, Johnson RJ: Uric acid stimulates monocyte chemoattractant protein1 production in vascular smooth muscle cells via mitogen-activated protein kinase and cyclooxygenase-2. Hypertension 2003;41:12871293.

-19 Tomita M, Mizuno S, Yamanaka H, Hosoda Y, Sakuma K, Matuoka Y, Odaka M, Yamaguchi M, Yosida H, Morisawa H, Murayama $\mathrm{T}$ : Does hyperuricemia affect mortality? A prospective cohort study of Japanese male workers. J Epidemiol 2000; 10:403-409.

20 Segura J, Campo C, Ruilope LM: How relevant and frequent is the presence of mild renal insufficiency in essential hypertension? J Clin Hypertens (Greenwich) 2002;4:332-336.

-21 Tseng CH: Correlation of uric acid and urinary albumin excretion rate in patients with type 2 diabetes mellitus in Taiwan. Kidney Int 2005; 68:796-801.

-22 Shigematsu Y, Hamada M, Hiasa G, Sasaki O, Ohtsuka T, Hashida H, Ikeda S, Suzuki M, Hara Y, Hiwada K: Serum creatinine level underestimates hypertensive renal involvement in elderly patients with essential hypertension. Hypertens Res 1999;22:297-301.

23 Hunsicker LG, Adler S, Caggiula A, England BK, Greene T, Kusek JW, Rogers NL, Teschan PE: Predictors of the progression of renal disease in the Modification of Diet in Renal Disease Study. Kidney Int 1997;51:1908-1919. 